\title{
Detecting the storage and change on topsoil organic carbon in grasslands of Inner Mongolia from 1980s to $2010 \mathrm{~s}$
}

\author{
DAI Erfu ${ }^{1}$, ZHAI Ruixue ${ }^{1,2}$, GE Quansheng ${ }^{1}$, WU Xiuqin ${ }^{3}$ \\ 1. Key Laboratory of Land Surface Pattern and Simulation, Institute of Geographic Sciences and Natural Re- \\ sources Research, CAS, Beijing 100101, China; \\ 2. University of Chinese Academy of Sciences, Beijing 100049, China; \\ 3. Beijing Forestry University, Beijing 100083, China
}

\begin{abstract}
Soil carbon sequestration and potential has been a focal issue in global carbon research. Under the background of global change, the estimation of the size as well as its change of soil organic carbon (SOC) storage is of great importance. Based on soil data from the second national soil survey and field survey during 2011-2012, by using the regression method between sampling soil data and remote sensing data, this paper aimed to investigate spatial distribution and changes of topsoil $(0-20 \mathrm{~cm})$ organic carbon storage in grasslands of Inner Mongolia between the 1980s and 2010s. The results showed that: (1) the SOC storage in grasslands of Inner Mongolia between the 1980s and 2010s was estimated to be 2.05 and $2.17 \mathrm{Pg} \mathrm{C}$, with an average density of 3.48 and $3.69 \mathrm{~kg} \mathrm{C} \cdot \mathrm{m}^{-2}$, respectively. The SOC storage was mainly distributed in the typical steppe and meadow steppe, which accounted for over $98 \%$ of the total SOC storage. The spatial distribution showed a decreased trend from the meadow steppe, typical steppe to the desert steppe, corresponding to the temperature and precipitation gradient. (2) SOC changes during 1982-2012 were estimated to be $0.12 \mathrm{Pg} \mathrm{C}$, at $7.00 \mathrm{~g} \mathrm{C} \cdot \mathrm{m}^{-2} \cdot \mathrm{yr}^{-1}$, which didn't show a significant change, indicating that SOC storage in grasslands of Inner Mongolia remained relatively stable over this period. However, topsoil organic carbon showed different trends of carbon source/sink during the past three decades. Meadow steppe and typical steppe had sequestered 0.15 and $0.03 \mathrm{Pg} \mathrm{C}$, respectively, served as a carbon sink; while desert steppe lost $0.06 \mathrm{Pg} \mathrm{C}$, served as a carbon source. It appears that SOC storage in grassland ecosystem may respond differently to climate change, related to vegetation type, regional climate type and grazing intensity. These results might give advice to decision makers on adopting suitable countermeasures for sustainable grassland utilization and protection.
\end{abstract}

Keywords: surface soil; organic carbon storage; climate change; spatial differences; grassland in Inner Mongolia

Received: 2014-07-12 Accepted: 2014-08-08

Foundation: The National Basic Research Program of China (973 Program), No.2011CB403206; No.2012CB416906; National Key Technology R\&D Program, No.2013BAC03B04

Author: Dai Erfu (1972-), PhD and Professor, specialized in comprehensive study of physical geography, climate change and regional response, simulation of LUCC. E-mail: daief@igsnrr.ac.cn 


\section{Introduction}

Soil was regarded as the largest organic carbon pool in terrestrial ecosystem. Estimates of SOC storage in the upper level of soils range from 1400 to $1500 \mathrm{Pg}$, which constitutes approximately two-thirds to three-fourths of the organic carbon in terrestrial ecosystems (Post et al., 1982; Schlesinger, 1990). Due to its huge storage capacity of SOC, even a slight change in it could have a significant impact on atmospheric $\mathrm{CO}_{2}$ concentration (Xu et al., 2011). To be one of the most widespread vegetation types worldwide, grasslands cover nearly one-fifth of the world's land surface (Lal, 2001). In grassland ecosystems, less than $10 \%$ of organic carbon is stored in the above biomass (Burke et al., 1997). The relatively large area of grasslands and huge SOC storage capacity make it a potentially important pool for carbon storage in terrestrial ecosystem. To detect carbon sequestration and its potential in grassland ecosystems would provide scientific basis for adaptation to global climate changes.

Research shows that grassland soil carbon storage occupies at least $10 \%-30 \%$ of the global soil carbon storage (Escaran et al., 1993; Anderson, 1991). Carbon storage in the soils of grasslands were previously studied based on different methods at a regional to global scale (Tao et al., 2006; Parton et al., 1995; Batjes, 1996; Jobbagy and Jackson, 2000; Ni, 2002; Zeng et al., 2004; Yang et al., 2010a; 2010b). Comparing those studies, we found that the results were not consistent, maybe because of different definitions of grassland and methods adopted. But all those works showed that grassland soils served as an important carbon pool (Scurlock and Hall, 1998). There is relatively little research on dynamics of SOC storage in grasslands of China and the existing estimates differ greatly. For the grasslands in northern China, Yang et al. (2010b) suggested that the SOC stock did not show a significant change by comparing current measurements with historical records derived from the Second National Soil Survey. In contrast, Xie et al. (2007) found SOC under grassland declined by $3.56 \mathrm{Pg}$ over the last 20 years, which northern grasslands accounted for $94.7 \%$.

The grasslands of Inner Mongolia are the main part of the temperate grasslands in northern China. The study of Inner Mongolia grasslands' SOC stocks and their changes over time are important for China carbon cycling research. Scientists have already launched studies on SOC cycle in Inner Mongolia, including study on the carbon cycle of leymus chinensis steppe in the Xilin River Basin (Li et al., 1998), spatial heterogeneity of soil moisture, carbon and nitrogen in stipa communities (Bai et al., 2002), spatial characteristics of SOC and nitrogen in Inner Mongolia (Chen et al., 2003). From the perspective of human disturbance, there are studies such as variation of below-ground carbon sequestration under long term cultivation and grazing in typical steppe (Yan et al., 2008), effects of grazing on SOC and total nitrogen in typical steppe (Liu and Zhang, 2010), response of soil respiration to grazing intensity, water contents, and temperature of soil in different grasslands of Inner Mongolia (Yang et al., 2012). SOC changes along a 50-year grassland-to-cropland conversion chronosequence in an agro-pastoral ecotone of Inner Mongolia (Jiao et al., 2012). The current researches on SOC are mainly conducted in connection with specific regions, the estimation of SOC storage and its changes are still very limited in Inner Mongolia.

Since combination of remote sensing data and field survey data is a new trend in current SOC storage estimation, Yang et al. (2009) detected the positive correlation between remote sensing data normalized difference vegetation index (NDVI) and SOC in the Tibetan alpine 
grasslands, and estimated the SOC storage and its changes using this satellite-based methodology. In this paper, based on soil data from the second soil survey of China and field survey during 2011-2012, we first establish the regression relation between soil data and remote sensing data. We then use ArcGIS plus this linear equation to explore the changes and its spatial distribution of SOC storage in grasslands of Inner Mongolia over the past 30 years. Therefore, the objectives of this study are to (1) estimate SOC storage in grasslands of Inner Mongolia for a depth of $20 \mathrm{~cm}$; (2) investigate the changes and its spatial distribution of SOC storage; (3) analyze the variation characteristics of SOC storage in grasslands of Inner Mongolia.

\section{Materials and methods}

\subsection{Study area}

The grasslands of Inner Mongolia $\left(38^{\circ}-51^{\circ} \mathrm{N}, 125^{\circ}-107^{\circ} \mathrm{E}\right)$ are located in the middle high latitudes of China, with an area of $58.77 \times 10^{4} \mathrm{~km}^{2}$, occupies $22 \%$ of the total grassland area, and is an important livestock husbandry base and green barrier (Dong and Zhang, 2005). This region has a temperate continental monsoon climate, with a mean annual temperature of -5 to $9^{\circ} \mathrm{C}$, annual precipitation of $100-450 \mathrm{~mm}$, and evaporation of $1200-2500 \mathrm{~mm}$. The temperature in Inner Mongolia shows a decreasing trend from south to north, while precipitation shows an increasing trend from southwest to northeast. The grasslands of Inner Mongolia belong to typical temperate semi-arid grassland and are located in the typical terrestrial transect - Northeast China transect of International Geosphere-Biosphere Program (IGBP) global change research, where is the most sensitive area to global change (Dong et al., 2000).

SOC in grassland ecosystems is mainly concentrated in the depth of $20 \mathrm{~cm}$, which is the most sensitive part to human activities under the background of global warming (Li et al., 1998; Zhou, 2006). Consequently, knowledge of SOC storage changes in grasslands would be needed for the evaluation of related policies and future decision-making.

The study area includes three types of grassland: meadow steppe, typical steppe and desert steppe, distributed from northeast to southwest (Figure 1). The meadow steppe is located at ectone between mountain coniferous forest and steppe, mainly distributed around Da Hinggan Mountains. The climate is sub-humid temperate type. The soil distribution is characterized by an obvious zonality, showing leached chernoze and chernozem from east to west, with gray forest soil developed under island forest. Its vegetation community is dominated by perennial mesophyte and xerophyte plants, and the constructive species include Stipa baicalensis, Filifolium sibiricum and Leymus chinensis. The typical steppe is distributed in the center of Inner Mongolian Plateau, making up the bulk of grasslands of the Inner Mongolia. The climate of this zone belongs to semi-arid temperate climate, and the main soil type is dark chestnut soil and typical chestnut soil. The vegetation is structured by typical perennial xerophyte plants with constructive species Stipa grandis, Stipa kryovii, Leymus chinensis and Stipa bungeana. The desert steppe is located in the east of Inner Mongolian Plateau, with an arid temperate climate. The soil types here consist of gray-brown desert soil, grey desert soil, sierozem and light brown calcic soil. The vegetation of desert steppe is formed by dwarf plants with strong drought-resistance. The constructive species are Stipa 
klemenzii, Stipa glareosa, Stipa breviflora, some degenerates into Allium polyrrhizum and Cleistogenes songoric.

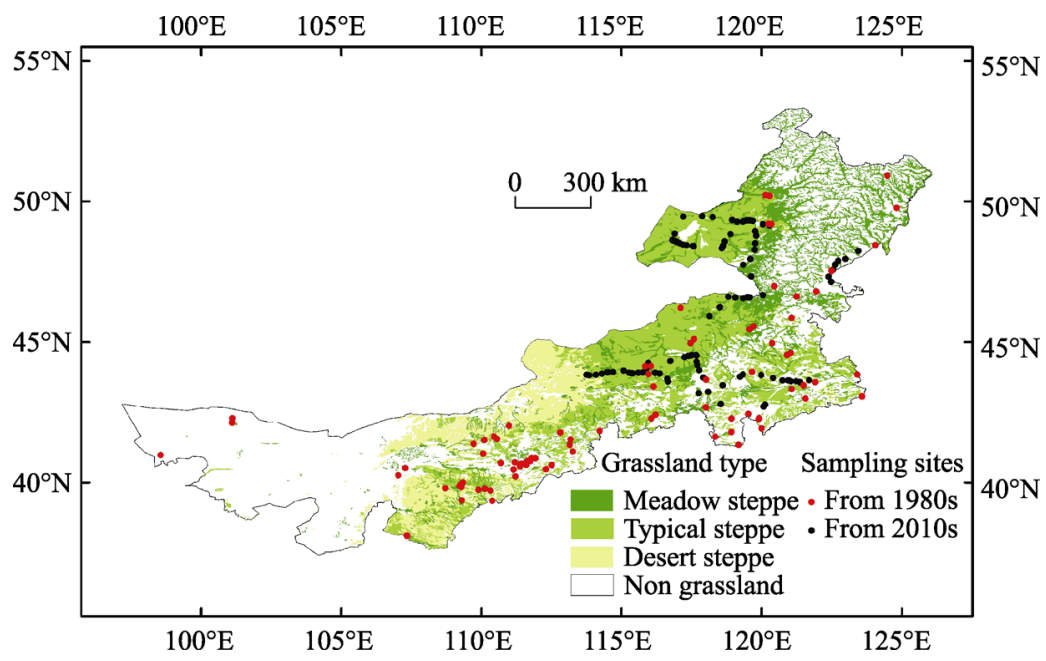

Figure 1 Grassland distribution and location of the sampling sites

\subsection{Data sources and processing}

The data used in this study include soil data, NDVI data and vegetation data, which is digitalized from the vegetation map of China $(1: 1,000,000)$. Soil data and NDVI data are handled as follows.

\subsubsection{Soil data}

Soil data was obtained from the Second National Soil Survey completed in the early 1980s and field survey during 2011-2012. A total of 80 grassland soil profiles were identified in the Second National Soil Survey, with a time span from 1982 to 1988. Information regarding the soil profiles include parameters on geological location, soil type, layer classification, soil depth, organic matter content, soil bulk density, percentage of the fraction $>2 \mathrm{~mm}$ and environment description. For most soil profiles, bulk density were lacked, so the missing data were derived from research of Chen et al. (2003). In order to obtain the current soil data, we sampled 306 soil profiles from 102 sites (i.e. three soil profiles at each site) at the depth of $20 \mathrm{~cm}$ in the representative zone of grasslands of Inner Mongolia during September 2011 and July 2012. Soil samples were taken to laboratory and air-dried, handpicked to remove the fine roots, and sieved $(0.25 \mathrm{~mm}$ mesh). The SOC concentration was measured by a wet combustion with $\mathrm{K}_{2} \mathrm{Cr}_{2} \mathrm{O}_{7}$. Soil moisture content and bulk density was estimated by oven-drying method that oven dried at $105 \pm 2^{\circ} \mathrm{C}$ to a constant mass.

\subsubsection{NDVI data}

Considering the availability of data, the NDVI datasets were consisted of two parts. One was produced by the Global Inventory Monitoring and Modeling Studies (GIMMS) group, at a spatial resolution of $8 \mathrm{~km} \times 8 \mathrm{~km}$ and 15-day interval, for the period of 1982-1988. The other was produced by Moderate-resolution Imaging Spectroradiometer (MODIS) group, at a spatial resolution of $0.05^{\circ} \times 0.05^{\circ}$ and 30-day interval, for the period of 2011-2012. Both data 
were quality guaranteed after geometric precision correction, radiometric calibration and atmospheric correction. The monthly NDVI database was obtained using the maximum value composition (MVC) method. Since the two NDVI datasets were derived from different sensors, it's necessary to check the consistency of two datasets. Through the linear regression analysis between the two datasets during overlap period (2000-2003) and the resampling methods, a spatial resolution of $8 \mathrm{~km} \times 8 \mathrm{~km}$ monthly NDVI values during 2011-2012 were obtained. After consistency test of the amendment NDVI with the corresponding MODIS NDVI, the corrected results passed the 0.05 confidence level test, and $\mathrm{R}^{2}$ is 0.95 (Zhang et al., 2013). Considering the climate characteristics and vegetation growth status in Inner Mongolia, the growing season is defined as May to September. The growing season NDVI was calculated as an average of the monthly NDVI for the periods of 1982-1988 and 2011-2012.

\subsection{Methods}

Soil organic carbon density (SOCD) refers to the organic carbon storage per unit area $\left(1 \mathrm{~m}^{2}\right)$ at a certain depth, it is the main basis for estimating SOC storage, also an important indicator of soil properties (Jin et al., 2001; Yang et al., 2011). In this paper, SOCD for $20 \mathrm{~cm}$ depth is calculated. The calculation was conducted by the following equation.

$$
S O C D=\sum_{i=1}^{n} 0.58 \times T_{i} \times B D_{i} \times S O M_{i} \times\left(1-C_{i}\right) / 100
$$

where $S O C D, T_{i}, B D_{i}, S O M_{i}$, and $C_{i}$ represent $\operatorname{SOCD}\left(\mathrm{kg} \mathrm{C} \cdot \mathrm{m}^{-2}\right)$, layer thickness $(\mathrm{cm})$, bulk density $\left(\mathrm{g} \cdot \mathrm{cm}^{-3}\right)$, soil organic matter $\left(\mathrm{g} \cdot \mathrm{kg}^{-1}\right)$, percentage of the fraction $>2 \mathrm{~mm}(\%)$ at layer $i$, respectively. 0.58 is the Bemmelen index that converts organic matter into organic carbon.

Because the soil layers of each profile in the Second National Soil Survey were investigated without a certain standard, SOM of different soil depth should be converted into SOM of $20 \mathrm{~cm}$. Here we adopt two kinds of methods depending on the situation, one is to calculate through the trend equation for soil profile, the second is using data directly when the surface soil layer $>20 \mathrm{~cm}$ or filling in the subsurface layer's data when the surface layer is less than $20 \mathrm{~cm}$.

After the calculation of SOCD, $80 \%$ of data points are randomly extracted to develop the relationship between SOCD and NDVI, and the remaining $20 \%$ are used to validate it. In this analysis, we used the above relationships to estimate SOCD for each pixel and document spatial distribution of SOCD for the two periods (1982-1988 and 2011-2012) respectively. We then calculated the difference between SOCD in the two periods for each pixel and obtained the distribution of the difference. Further, we overlaid the vegetation map over the distribution of SOCD and its difference to obtain the sizes and their changes of SOCD for meadow steppe, typical steppe and desert steppe.

\section{Results and analysis}

\subsection{Relationship between NDVI and SOCD}

Some $80 \%$ of data points were randomly extracted to develop the relationship between SOCD and NDVI, and the results were as follows: 


$$
\begin{gathered}
S O C D=13.137 N D V I-1.3467 \quad\left(R^{2}=0.5396, P<0.0001\right) \\
S O C D=20.432 N D V I-4.1711 \quad\left(R^{2}=0.53, P<0.0001\right)
\end{gathered}
$$

The remaining $20 \%$ were used to compare with predicted data derived from the above relationship, and the results were shown in Figure 2. The correlation coefficients were $0.7942(\mathrm{P}<0.0001)$ and $0.5952(\mathrm{P}<0.0001)$ respectively.
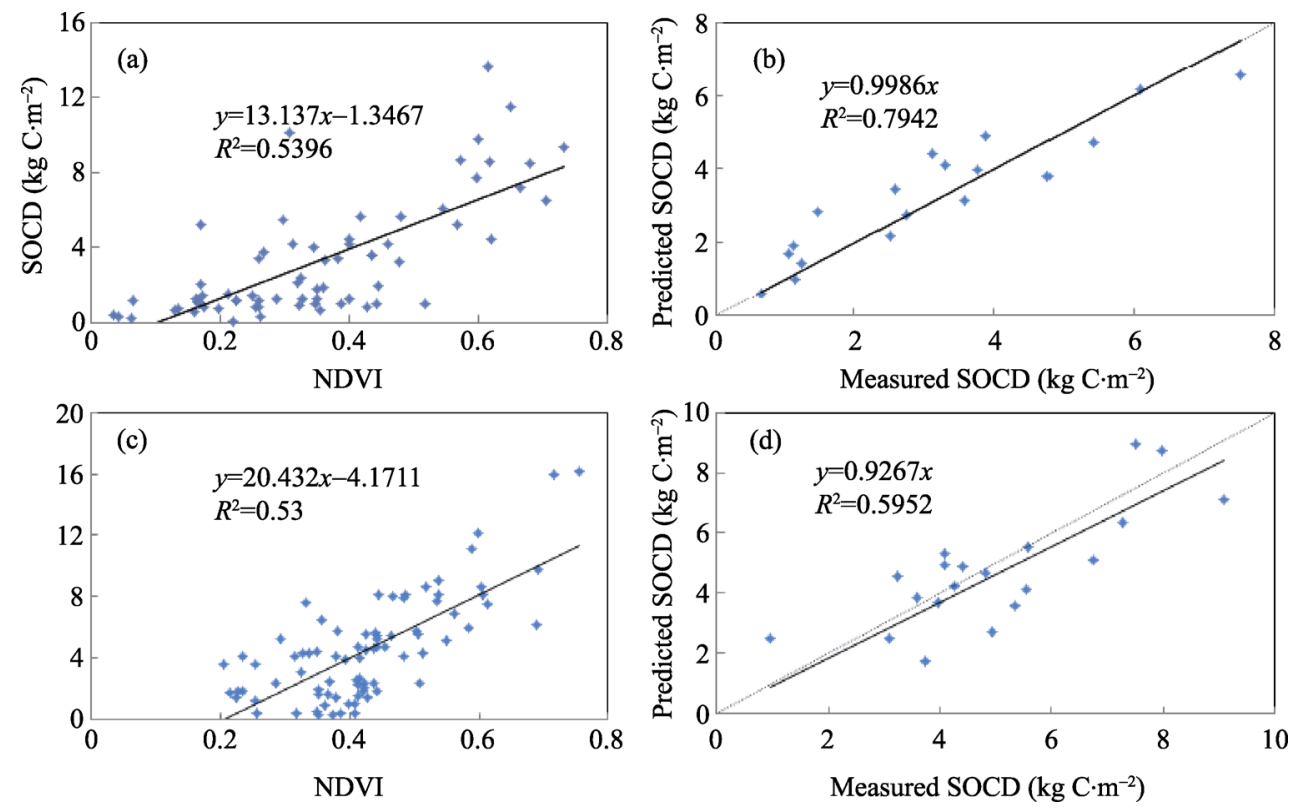

Figure 2 The relation of NDVI \& SOCD and comparison between predicted and measured SOCD in the 1980s (a) (b) and 2010s (c) (d)

The results indicated that the predicted SOCD was well consistent with measured value, with a correlation coefficient of 0.5396 and 0.53 for the relationships during the period of 1982-1988 and 2011-2012. This demonstrates that this method is suitable for estimating regional SOC storage, and also shows topsoil organic carbon is closely related to the above-ground vegetation, because SOC values are mainly derived from the above-ground litter and root decomposition.

\subsection{SOC storage}

Using the relationships between SOCD and NDVI, we estimated the topsoil organic carbon density and storage in grasslands of Inner Mongolia. Table 1 lists the SOC density and storage for the major grassland types in Inner Mongolia. The results indicated the SOC storage in the $1980 \mathrm{~s}$ and $2010 \mathrm{~s}$ were $2.05 \mathrm{Pg} \mathrm{C}$ and $2.17 \mathrm{Pg} \mathrm{C}$, with an average SOCD of 3.48 $\mathrm{kg} \mathrm{C} \cdot \mathrm{m}^{-2}$ and $3.69 \mathrm{~kg} \mathrm{C} \cdot \mathrm{m}^{-2}$, respectively. The SOC storage was mainly distributed in the typical steppe and meadow steppe, which held more than $98 \%$ of the total SOC storage. The SOCD was decreased from meadow steppe, typical steppe to desert steppe. The typical steppe had a large organic carbon reserves owing to its vast area. In the $2010 \mathrm{~s}$, the estimated SOC densities in meadow steppe, typical steppe and desert steppe were $6.65,3.41,0.27$ $\mathrm{kg} \mathrm{C} \cdot \mathrm{m}^{-2}$, respectively. Based on field survey data in 2001-2005, Yang et al. (2010b) calcu- 
lated the organic carbon at a depth of $30 \mathrm{~cm}$. Their estimates of three grassland types were $6.97,4.08$ and $2.46 \mathrm{~kg} \mathrm{C} \cdot \mathrm{m}^{-2}$, respectively. Compared to their study, the estimate of typical steppe in this paper was in accordance with the soil profile feature, the estimate of meadow steppe was relatively high and the estimate of desert steppe was much lower. The differences of carbon estimates between this study and the previous studies are probably due to the distribution of sampling sites. The sampling sites in this paper were mainly distributed in the meadow steppe and typical steppe while Yang et al.'s study was mainly concentrated in the typical steppe and desert steppe.

Table 1 Topsoil organic carbon stocks in grasslands of Inner Mongolia during the 1980s-2010s

\begin{tabular}{|c|c|c|c|c|c|}
\hline \multirow{2}{*}{ Grassland type } & \multirow{2}{*}{$\begin{array}{c}\text { Area } \\
\left(10^{4} \mathrm{~km}^{2}\right)\end{array}$} & \multicolumn{2}{|c|}{ SOC storage (1982-1988) } & \multicolumn{2}{|c|}{ SOC storage (2011-2012) } \\
\hline & & Density $\left(\mathrm{kg} \mathrm{C} \cdot \mathrm{m}^{-2}\right)$ & Storage (Pg C) & Density $\left(\mathrm{kg} \mathrm{C} \cdot \mathrm{m}^{-2}\right)$ & Storage $(\mathrm{Pg} \mathrm{C})$ \\
\hline Meadow steppe & 17.25 & 5.80 & 1.00 & 6.65 & 1.15 \\
\hline Typical steppe & 28.96 & 3.31 & 0.96 & 3.41 & 0.99 \\
\hline Desert steppe & 12.56 & 0.70 & 0.09 & 0.27 & 0.03 \\
\hline Total & 58.77 & 3.48 & 2.05 & 3.69 & 2.17 \\
\hline
\end{tabular}

Yang et al. (2010b) reported that the organic carbon density of $30 \mathrm{~cm}$ topsoil in northern China's grasslands was about $5.33 \mathrm{~kg} \mathrm{C} \cdot \mathrm{m}^{-2}$. By contrast, the SOCD in grasslands of Inner Mongolia was slightly lower than that of northern China's grasslands. Xie et al. (2004) estimated the total organic carbon storage of $20 \mathrm{~cm}$ topsoil in China was around $27.4 \mathrm{Pg} \mathrm{C}$, with an overall average density of $2.96 \mathrm{~kg} \mathrm{C} \cdot \mathrm{m}^{-2}$. Therefore, SOCD of grasslands of Inner Mongolia is higher than the overall level of China, and the total storage occupies about $7.5 \%$ of organic carbon reserves in China.

SOCD exhibited large spatial heterogeneity in grasslands of Inner Mongolia, decreasing from northeast to southwest, negatively correlated with temperature and positively correlated with precipitation (Figure 3). The lowest SOCD was in desert steppe, close to 0 . The condition of poor precipitation and low vegetation coverage led to the lower SOCD in this region. The highest SOCD was in meadow steppe, due to its relatively low temperature and favorable precipitation and hence high vegetation coverage and primary productivity. Thus, the grasslands of Inner Mongolia formed a distribution pattern of the northeast region as the high-density center and southwest region as the low-density center, which is in accordance with Chen et al.'s study (2003).

\subsection{The changes of SOC}

In the last 30 years, SOC storage in the study area showed a slight increase of $0.12 \mathrm{Pg} \mathrm{C}$ (Table 2). The meadow steppe acted as a carbon sink, with an SOC increase of $0.15 \mathrm{Pg} \mathrm{C}$, at a rate of $28.33 \mathrm{~g} \mathrm{C} \cdot \mathrm{m}^{-2}$; the typical steppe acted as a carbon sink, with an SOC increase of $0.03 \mathrm{Pg} \mathrm{C}$, at a rate of $3.33 \mathrm{~g} \mathrm{C} \cdot \mathrm{m}^{-2}$; The desert steppe acted as a carbon source, with an SOC decrease of $0.06 \mathrm{Pg} \mathrm{C}$, at a rate of $-14.33 \mathrm{~g} \mathrm{C} \cdot \mathrm{m}^{-2}$.

The slight increase of SOC during 1982-2012 did not show a significant change, indicating that SOC storage in grasslands of Inner Mongolia remained relatively stable over this period. The total biomass in northern China's grasslands also exhibited a weak increasing 

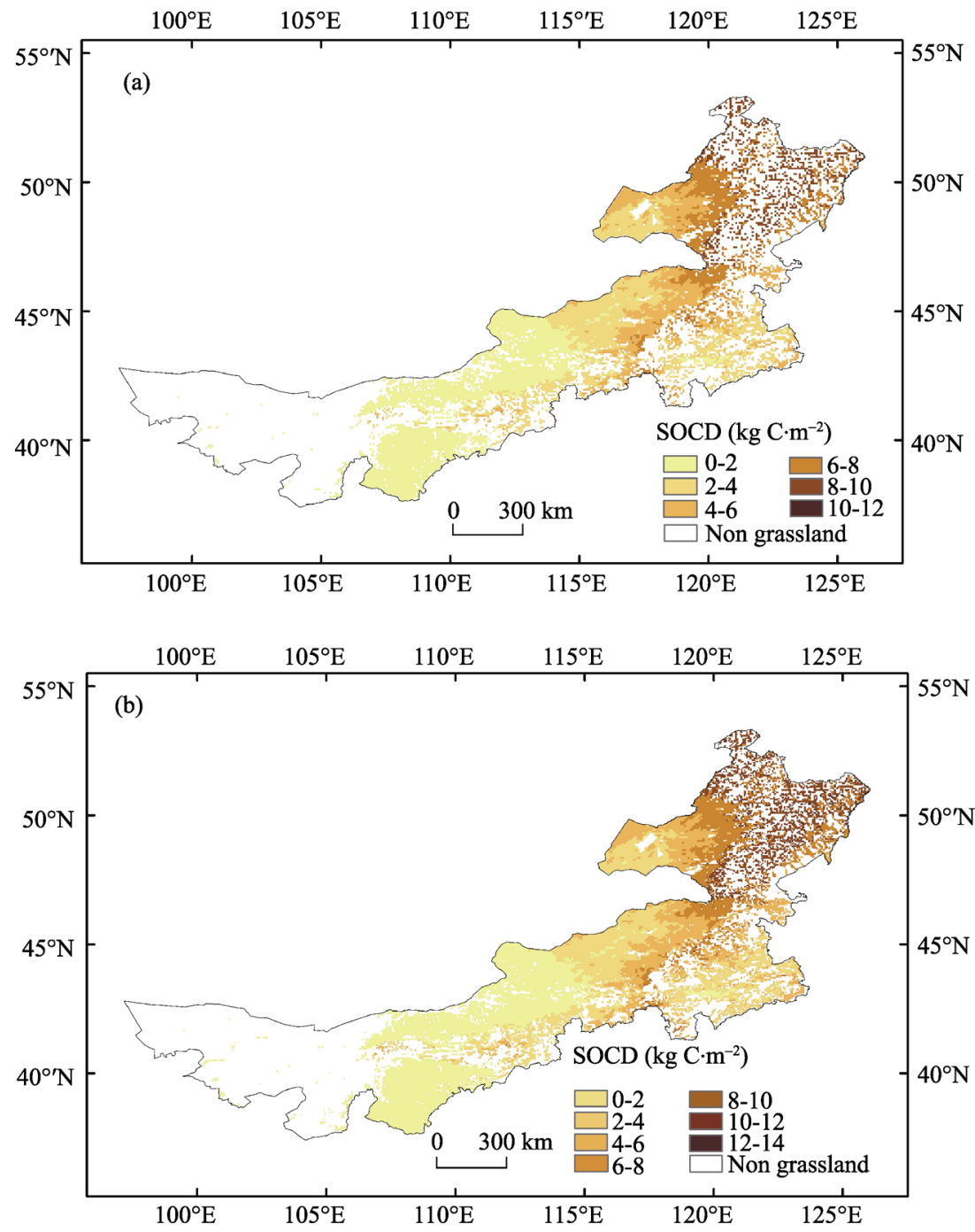

Figure 3 Topsoil organic carbon density in grasslands of Inner Mongolia in the 1980s (a) and 2010s (b)

Table 2 Changes of topsoil organic carbon stocks in grasslands of Inner Mongolia during the 1980s-2010s

\begin{tabular}{ccccc}
\hline \multirow{2}{*}{ Grassland type } & Area $\left(10^{4} \mathrm{~km}^{2}\right)$ & \multicolumn{3}{c}{ Changes in SOC $(1980 \mathrm{~s}-2010 \mathrm{~s})$} \\
\cline { 3 - 5 } & & Variation $\left(\mathrm{kg} \mathrm{C} \cdot \mathrm{m}^{-2}\right)$ & Rate $\left(\mathrm{g} \mathrm{C} \cdot \mathrm{m}^{-2} \cdot \mathrm{yr}^{-1}\right)$ & Total $(\mathrm{Pg} \mathrm{C})$ \\
\hline Meadow steppe & 17.25 & 0.85 & 28.33 & 0.15 \\
Typical steppe & 28.96 & 0.10 & 3.33 & 0.03 \\
Desert steppe & 12.56 & -0.43 & -14.33 & -0.06 \\
Total & 58.77 & 0.21 & 7.00 & 0.12 \\
\hline
\end{tabular}

trend and increased from 531.6 Tg C in 1982-1986 to 557.5 Tg C in 2002-2006 (Ma et al., 2010). Although the warm climate stimulating SOC decomposition, the increase of nitrogen availability and vegetation inputs can promote carbon sequestration. Furthermore, grazing can lower vegetation coverage and reduce the carbon input, but new forms of carbon input 
such as animal manure may weaken this effect (Susane, 1997; Sun et al., 2010).

The decreasing area of SOCD was mainly distributed in desert steppe. $74.9 \%$ of total pixels in meadow steppe and $52.4 \%$ in typical steppe showed an increase, whereas $18.7 \%$ in desert steppe showed an increase (Figure 4). The spatial heterogeneity of SOC changes indicates that grassland ecosystems may respond differently to climate change depending on vegetation type, regional climate type and grazing intensity. Research in the Tibetan Plateau has the similar conclusion (Yang et al., 2009).

The formation of carbon sink/source depends on the balance of carbon sequestration and soil respiration. Desert steppe is more vulnerable and more sensitive to global warming, with increasing temperature accelerating the decomposition of carbon and increasingly drying environment affecting the growth of plants, developing into a carbon source. Meadow steppe is distributed in a more humid environment; the positive effect of temperature rise is more obvious, therefore meadow steppe behaved as a carbon sink. As the typical steppe belongs to semi-arid regions, the positive effects may have been compensated by negative effects, resulting in a slight increase in carbon storage. Susane (1997) suggested that the soil carbon pool contained three components with different turnover times-active pool, intermediate pool, passive pool, and the responding parts to global changes were active pool and intermediate pool. Therefore, we can start the study of grassland response mechanisms from active pool and intermediate pool. Till now little relevant research have been done in China (Wang et al., 2009; Hua et al., 2009; Jiao et al., 2009), it may become a new research direction in the future.

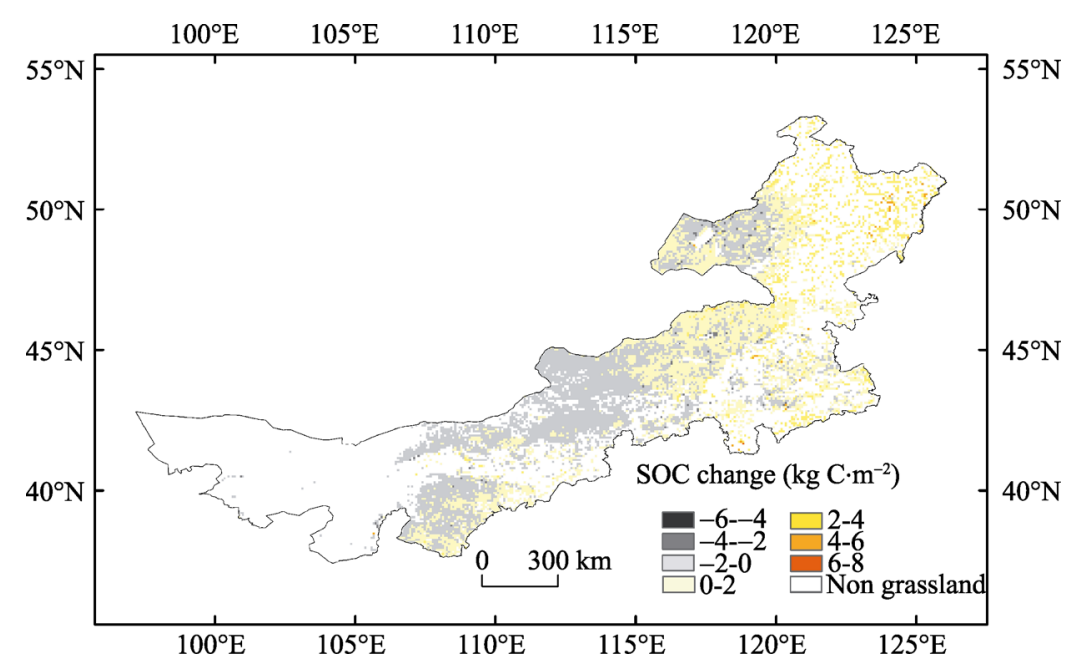

Figure 4 Changes of topsoil organic carbon density in grasslands of Inner Mongolia during the 1980s-2010s

\section{Conclusions and discussion}

Based on the relationship between NDVI and SOCD, we estimated the sizes and the changes of topsoil organic carbon pool in grasslands of Inner Mongolia over the last three decades. The conclusions are as follows:

(1) The statistical test and analysis of equation results indicated that the predicted SOCD was well consistent with measured value, meaning this method can calculate SOC storage 
and its dynamic scientifically.

(2) SOC storage in grasslands of Inner Mongolia between the 1980s and 2010s was estimated to be 2.05 and $2.17 \mathrm{Pg} \mathrm{C}$, with an average density of 3.48 and $3.69 \mathrm{~kg} \mathrm{C} \cdot \mathrm{m}^{-2}$, respectively. The spatial distribution showed a decreased trend from the meadow steppe, typical steppe to the desert steppe, corresponding to the temperature and precipitation gradient.

(3) SOC changes during 1982-2012 were estimated to be $0.12 \mathrm{Pg} \mathrm{C}$, indicating that SOC storage in grasslands of Inner Mongolia remained relatively stable over this period. However, topsoil organic carbon of different grassland ecosystem showed different trends of carbon source/sink during the past three decades. Meadow steppe and typical steppe had sequestered 0.15 and $0.03 \mathrm{Pg} \mathrm{C}$, respectively, served as a carbon sink; while desert steppe had lost $0.06 \mathrm{Pg} \mathrm{C}$, served as a carbon source. It appears that SOC storage in grassland ecosystem may respond differently to climate change, related to vegetation type, regional climate type and grazing intensity.

Generally, the relationship-based SOC assessment can reduce the uncertainties derived from the large soil heterogeneity, but some uncertainties and application restricts still exist. Due to different data sources, regional differences and other factors, the estimates of grassland SOC storage are quite different. Our findings demonstrated that NDVI was positively correlated with SOCD in grassland ecosystems of Inner Mongolia. In the study of the major grassland types in Alex, Inner Mongolia, Fu et al. (2004) found that the most important factors affecting SOC in the $0-20 \mathrm{~cm}$ layer were plant cover, plant productivity and annual precipitation, and the partial correlation coefficients were $0.777,0.697$ and 0.429 , respectively, reflecting the close relation between SOCD and NDVI. Our study calculate soil carbon storage through the relationship between SOCD and remote sensing data, the uncertainty of our findings include: (1) Remote sensing data used in this study are derived from two kinds of datasets: GIMMS and MODIS; the data conversion process will produce some errors. (2) Most soil profiles lacked the bulk density data in the Second National Soil Survey. In the previous studies, some use the relationship between bulk density and SOC concentration to estimate bulk density; some use the recent field survey data. In this paper, the lacked bulk density was obtained from related research, we use the soil bulk density of belonging soil subtypes to replace the missing data. (3) The 2010s' sampling sites were mainly set in meadow steppe and typical steppe and little in desert steppe. Thus, compared with the 1980s, the correlation coefficient between predicted and measured values in the 2010s was relatively lower, which caused a potential uncertainty in estimating SOCD of desert steppe. However, considering the low proportion of desert grassland area and its low SOCD, it merely exerts little influence on the total SOC storage, especially for topsoil. These error sources suggest that more reliable field survey data and scientific model are required to improve our understanding on sizes and changes of SOC storage in the future study.

The dynamic process of grassland SOC contains two parts. One is carbon input - the humus forming process fixed carbon into soils, the other is carbon output acting as soil respiration. On the micro level, the micro-climates in soils affect organic matter's decomposition rates, and then control the formation and decomposition of SOC to some extent (Yang et al., 2011). On the macro level, climate conditions and human activities are the main factors impacting grassland soil carbon storage. Climate change alters temperature, precipitation, $\mathrm{CO}_{2}$ concentration and other environmental factors. Human activities (cultivation, grazing, 
mowing, etc.) also have an impact on grassland carbon storage, mostly exerting a negative influence. Our study found that the soil organic carbon storage in grasslands of Inner Mongolia were slightly increased over the past 30 years, but the main driving factors and their role in the process remain to be investigated.

The relationship between terrestrial ecosystems and the global carbon cycle is the front edge and hot spot in global change research, a lot of studies have been developed to estimate the grassland soil carbon pool. According to IPCC "B2 mid-low emission scenario", the regional climate model predicts that the temperature in China in the 2020s, 2040s, and 2070s will rise by $1.16,2.20$, and $3.20^{\circ} \mathrm{C}$, the corresponding precipitation increases are $3.7 \%, 7.0 \%$, and $10.2 \%$, respectively, as well as decrease in extreme cold damage, and increase in extreme heat (IPCC, 2007). Under such future climate change scenarios, how grassland soil carbon pool will change, how different grassland ecosystems will response, what kind of short-term and long-term effects will produce, all these questions need further study.

\section{References}

Anderson J M, 1991. The effects of climate change on decomposition processes in grassland and coniferous forest. Ecological Applications, 1: 326-337.

Bai Y F, Xu Z X, Li D X, 2002. On the small scale spatial heterogeneity of soil moisture, carbon and nitrogen in stipa communities of the Inner Mongolia Plateau. Acta Ecologica Sinica, 22(8): 1209-1217. (in Chinese)

Batjes N H, 1996. Total carbon and nitrogen in soils of the world. European Journal of Soil Science, 47(2): $151-163$.

Burke I C, Lauenroth W K, Milchunas D G, 1997. Biogeochemistry of Managed Grasslands in Central North America. Boca Raton: CRC Press, 85-102.

Chen Q M, Wang S Q, Yu G R, 2003. Spatial characteristics of soil organic carbon and nitrogen in Inner Mongolia. Chinese Journal of Applied Ecology, 14(5): 699-704. (in Chinese)

Dong X B, Zhang X S, 2005. The grassland in the Inner Mongolia is overloaded and changes of the production pattern are highlighted. Resources Science, 27(4): 175-179. (in Chinese)

Dong Y S, Zhang S, Qi Y S et al., 2000. Study on the $\mathrm{CO}_{2}, \mathrm{~N}_{2} \mathrm{O}, \mathrm{CH}_{4}$ flux characteristics and diurnal variation in a typical grassland of Inner Mongolia. Chinese Science Bulletin, 45(3): 318-322. (in Chinese)

Escaran H, Vanden B E, Reich P, 1993. Organic carbon in soils of the world. Soil Science Society of America Journal, 57: 192-196.

$\mathrm{Fu}$ H, Chen Y M, Wang Y R et al., 2004. Organic carbon content in major grassland types in Alex, Inner Mongolia. Acta Ecologica Sinica, 24(3): 469-476. (in Chinese)

Hua J, Zhao S W, Zhang Y et al., 2009. Distribution characteristics of soil labile organic carbon of different grassland communities in Yunwu Mountain. Acta Agrectir Sinica, 17(3): 315-320. (in Chinese)

IPCC, 2007. Special Report on Emissions Scenarios (SRES). Cambridge: Cambridge University Press.

Jiao Y, Xu Z, Zhao J H et al., 2012. Changes in soil carbon stocks and related soil properties along a 50-year grassland-to-cropland conversion chronosequence in an agro-pastoral ecotone of Inner Mongolia, China. Journal of Arid Land, 4(4): 420-430.

Jiao Y, Zhao J H, Xu Z, 2009. Effects of land use changes on soil physi-chemical properties in farm-grazing transition belt of Inner Mongolia autonomous region. Acta Agrectir Sinica, 17(2): 234-238. (in Chinese)

Jin F, Yang H, Cai Z C et al., 2001. Calculation of density and reserve of organic carbon in soils. Acta Pedologica Sinica, 38(4): 522-528. (in Chinese)

Jobbagy E G, Jackson R G, 2000. The vertical distribution of soil organic carbon and its relation to climate and vegetation. Ecol. Appl., 10: 470-483.

Lal R, 2001. Potential of desertification control to sequester carbon and mitigate the greenhouse effect. Climatic 


\section{Change, 51(1): 35-72.}

Li L H, Liu X H, Chen Z Z, 1998. Study on the carbon cycle of Leymus chinensis steppe in the Xilin River Basin. Acta Botanica Sinica, 40(10): 955-961. (in Chinese)

Liu N, Zhang Y J, 2010. Effects of grazing on soil organic carbon and total nitrogen in typical steppe. Pratacultural Science, 27(4): 11-14. (in Chinese)

Ma W H, Fang J Y, Yang Y H et al., 2010. Biomass carbon stocks and their changes in northern China's grasslands during 1982-2006. Science China Life Sciences, 53(7): 841-850. (in Chinese)

Ni J, 2002. Carbon storage in grasslands of China. Arid Environment, 50(2): 205-218.

Parton W J, Scurlock J M O, Ojima D S et al., 1995. Impact of climate change on grassland production and soil carbon worldwide. Global Change Biol., 1(1): 13-22.

Post W M, Emanuel W R, Zinke P J et al., 1982. Soil carbon pools and world life zones. Nature, 298(8): 156-159.

Schlesinger W H, 1990. Evidence from chronoseauence studies for a low carbon-storage potential of soil. Nature, 348(15): 232-234.

Scurlock J M O, Hall D O, 1998. The global carbon sink: A grassland perspective. Global Change Biology, 4: 229-233.

Sun J Y, Peng S S, Wang X H et al., 2010. NDVI based space-time change in global vegetation growth from 1982 to 2006. Quaternary Sciences, 30(3): 522-530. (in Chinese)

Susane T, 1997. Potential responses of soil organic carbon to global environmental change. PNAS, 94(16): 8284-8291.

Tao Z, Shen C D, Gao Q Z et al., 2006. Soil organic carbon storage and vertical distribution of alpine meadow on the Tibetan Plateau. Acta Geographica Sinica, 61(7): 720-728. (in Chinese)

Wang J L, Ouyang H, Wang Z H et al., 2009. Distribution of soil active organic carbon of alpine grassland on Qinghai-Tibet Plateau. Acta Geographica Sinica, 64(7): 771-781. (in Chinese)

Xie X L, Sun B, Zhou H Z et al., 2004. Organic carbon density and storage in soils of China and spatial analysis. Acta Pedologica Sinica, 41(1): 35-47. (in Chinese)

Xie Z B, Zhu J G, Liu G et al., 2007. Soil organic carbon stocks in China and changes from 1980s to 2000s. Global Change Biology, 13(9): 1989-2007. (in Chinese)

Xu N Z, Liu Y, Wei F, 2011. Research progress on soil carbon pool and its changes. Jiangsu Agricultural Sciences, 39(2): 1-5. (in Chinese)

Yan Y C, Song C C, Chang R Y et al., 2008. Variation of below-ground carbon sequestration under long term cultivation and grazing in the typical steppe of Nei Monggol in north China. Environmental Science, 29(5): 1388-1393. (in Chinese)

Yang H F, Mu S J, Sun C M et al., 2011. Summary of research on estimation of organic carbon storage in grassland ecosystem. Chinese Journal of Grassland, 33(5): 107-114. (in Chinese)

Yang Y, Han G D, Li Y H et al., 2012. Response of soil respiration to grazing intensity, water contents, and temperature of soil in different grasslands of Inner Mongolia. Acta Prataculturae Sinica, 21(6): 8-14. (in Chinese)

Yang Y H, Chen Y N, Li W H et al., 2010a. Soil organic carbon distribution of different vegetation types in the Ili River Valley. Acta Geographica Sinica, 65(5): 605-612. (in Chinese)

Yang Y H, Fang J Y, Ma W H et al., 2010b. Soil carbon stock and its changes in northern China's grasslands from 1980s to 2000s. Global Change Biol., 16(11): 3036-3047.

Yang Y H, Fang J Y, Tang Y H et al., 2009. Changes in topsoil carbon stock in the Tibetan grasslands between the 1980s and 2004. Global Change Biology, 15(11): 2723-2729.

Zeng Y N, Feng Z D, Cao G C et al., 2004. The soil organic carbon storage and its spatial distribution of alpine grassland in the source region of the Yellow River. Acta Geographica Sinica, 59(4): 497-504. (in Chinese)

Zhang Q Y, Zhao D S, Wu S H et al., 2013. Research on vegetation changes and influence factors based on eco-geographical regions of Inner Mongolia. Scientia Geographica Sinica, 33(5): 594-600. (in Chinese)

Zhou Z Y, 2006. Effects of land use on agro-pastoral ecotone in Inner Mongolia grassland ecosystem [D]. Beijing: Institute of Botany, the Chinese Academy of Sciences, 41-45. (in Chinese) 